\title{
Sessizliğin Sesi Olabilmek Adına Bir Önerme: QR Kod Baskılı Giysiler
}

\author{
Leyla YILDIRIM *, Özlem CÖMERTPAY**
}

\section{Giriş}

Tekstiller üretildiklerin dönemlerden günümüze çeşitli mesajların iletilmesinde birer gösterge görevi görmüşlerdir. İlkel toplumlardan modern toplumlara gerek desenleri, gerek renkleri gerekse modelleri ile toplumsal statü, ait olunan grup, cinsel kimlik vb. gibi çeşitli durum ve bilgiyi ileten birer kod işlevine sahip olmuşlardır.

Akıllı telefonlar ve bunlarla kullanılan yeni uygulamalar insan-nesne-çevre arasındaki iletişimin boyutu değiştirmiş, mesajı iletenin algılayanın ve taşıyanın bu yeni teknolojilere uyum sağlama zorunluluğunu getirmiştir.

Teknolojinin sağladığı olanaklar, her geçen gün artmakla birlikte, bu olanakların uygulama alanlarının genişletilmesi ve toplum yararına kullanılmalarının arttırılması önemli bir konudur.

Geniş kullanım alanına sahip QR kod (Quick Response) teknolojisi, web sitesi adresi, mesaj, metin, etkinlik takvimi, telefon numarası, konum bildirimi gibi çeşitli bilgileri taşıyabilmektedir (Rewatkar and Raut, 2014: 1320). Taşıdığı bilgiler pazarlamadan eğlenceye, kütüphane hizmetlerinden mezarlıklara kadar birçok alanda kullanılabilmektedir.

QR kod'un grafik bir etiketleme olarak estetik özelliği üzerine çalışmalar bulunduğu gibi (Yi-Shan Lin vd. 2013:1; Hung-Kuo Chu vd. 2013:1-8) Michele Pred, Pedro Morales gibi QR kod'un estetik özelliğinden yararlanarak mesaj ileten sanatçılar da bulunmaktadır (O'Callaghan Simone, 2009:1-6; Kevin, 2012: 4). QR kod'un sunduğu olanaklar tekstil tasarımcıları tarafından da araştırılmakta akıllı teknolojilerle zanaat çalışmalarının birleştirilmesine dair yeni bakış açıları sunulmaya çalışılmaktadır. Örneğin Estonya'nın geleneksel giysisi olan Muhu eteğin, QR kod'a benzer şekilde desen ve motifleriyle çeşitli anlamlar taşıması arasında bir bağ kurularak nakış tekniği ile QR kod uygulamaları yapılmıştır. Üç prototipten oluşan $Q R$ kod uygulamalarının birincisinde kullanılan malzemenin yaşam döngüsü, ikincisinde geleneğin kodlaştırılmasına örnek bir masal ve üçüncüsünde bölgeye ait erdemleri içeren atasözü ve deyim yer almıştır (Kuusk vd., 2014:1-12).

Guillermo Bert, tekstillerin içerdiği mesajlardan yola çıkarak QR kod desenli tapestry'ler yapmakta hem QR kod'un estetik hem de işlevsel değerine metaforik yaklaşmaktadır (Resim 1).

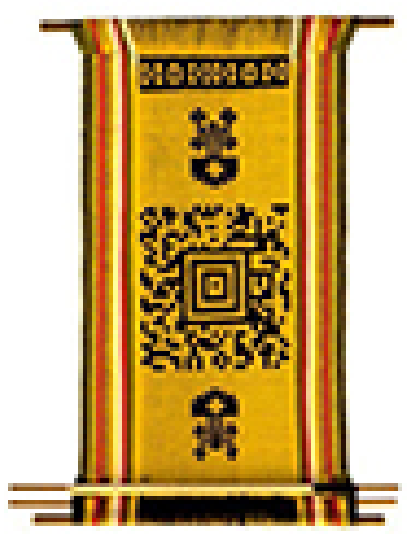

Resim 1. Lukutuwe (Fertility), Guillermo Bert 2012.

QR kod'un tekstil tasarımında baskı, örme, nakış, boncuk işleme, patchwork vb. tekniklerle uygulandığına dair çeşitli örneklere rastlamak mümkündür (Resim 2-5). 


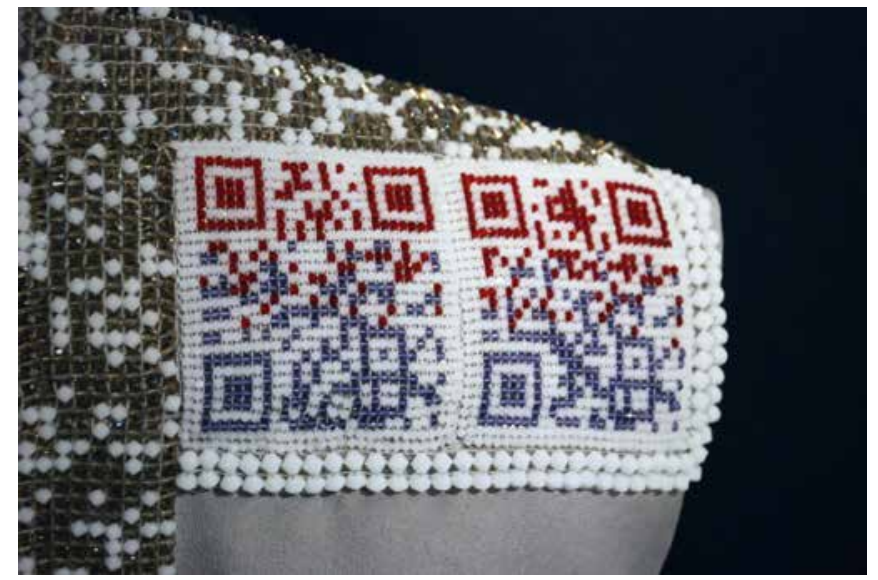

Resim 2. Boncuk işlemeli barkod, Thorunn Arnadottir, 2011

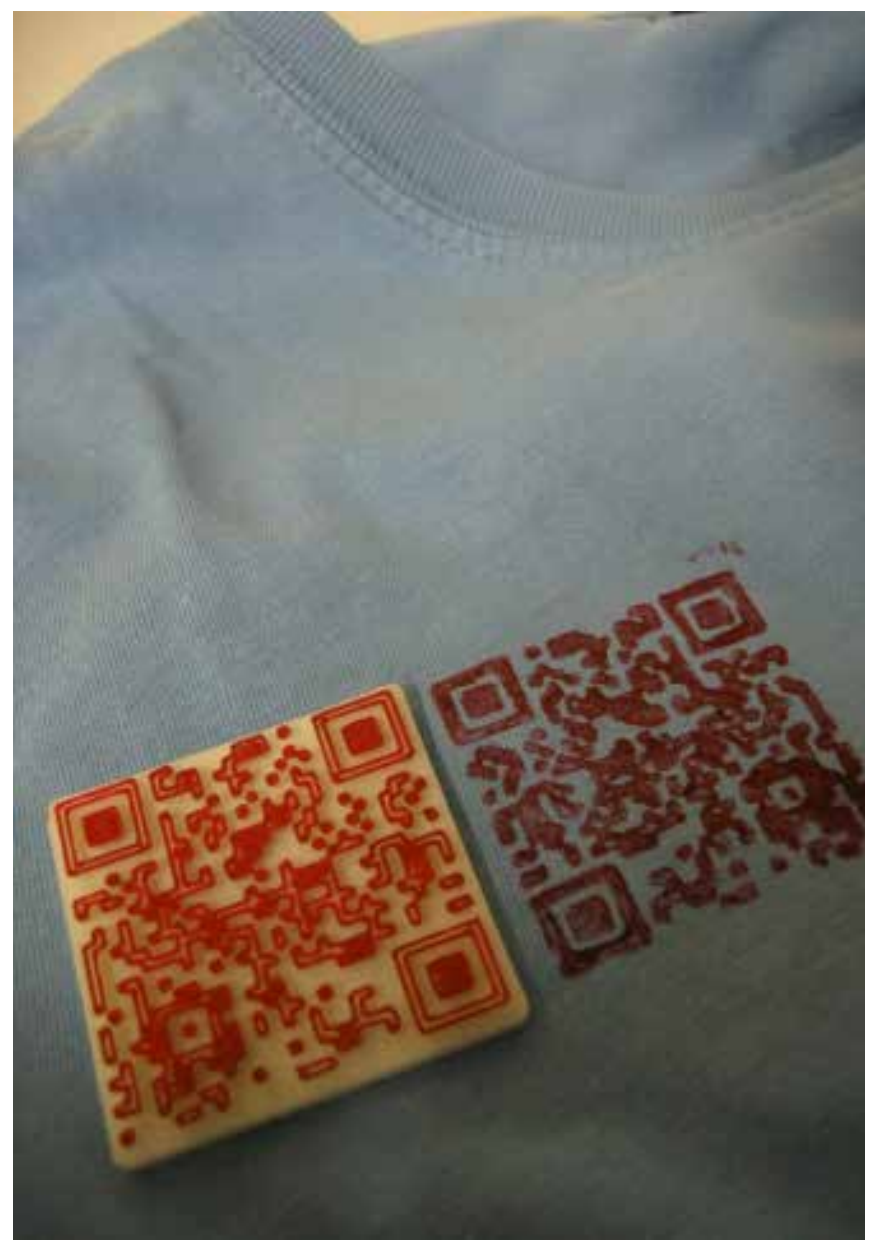

Resim 3. Baskı tekniği ile QR kod uygulaması, Vincent Simoncelli, 2011

Gerek bireyler gerekse kurumlar istediklerinde kendilerine özel QR kodlar oluşturabilecekleri gibi; akıllı te-

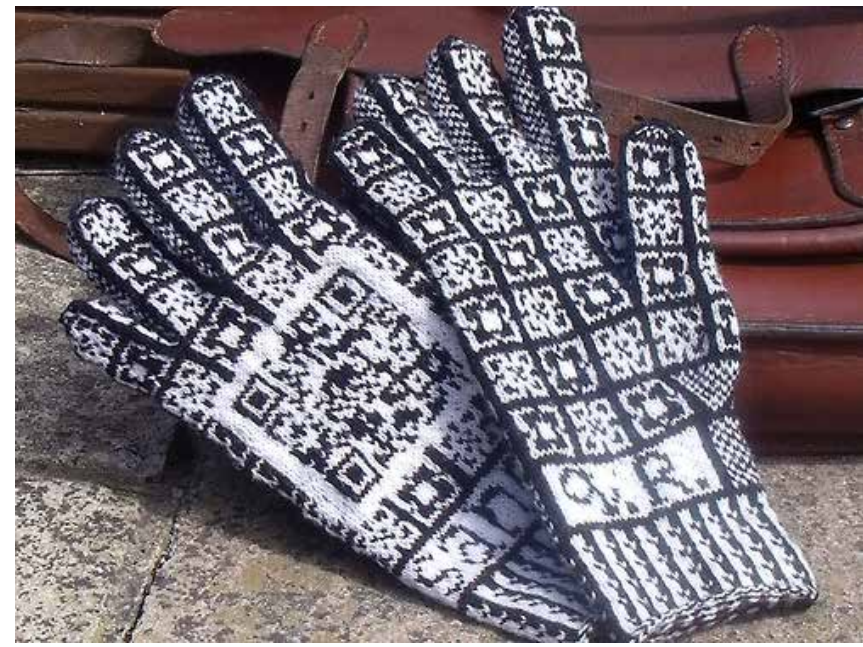

Resim 4.QR desenli eldiven, Donna Druchunas, 2015

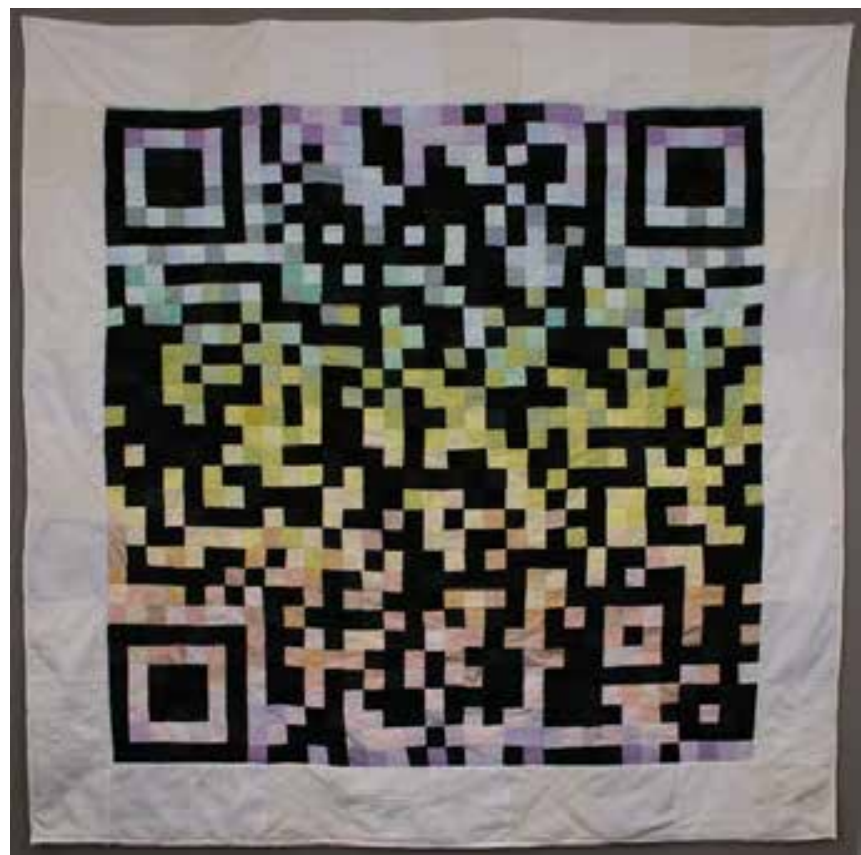

Resim 5. Rubi McGrory, Patchwork, 2010

lefonlara indirilen kod okuyucu tarayıcılar tarafından istedikleri kodları da oluşturabilmektedirler (Winter Mick, 2011: 22-27).

\section{Amaç Ve Yöntem}

Lisans bitirme projesi olan bu çalışmada öğrenci, internet üzerinden ve etrafındaki kaynak kişilerden elde ettiği bilgiler ışığında işitme engelli bireylerin sorunlarını tespit etmiş, QR kod baskılarıyla bu sorunları dile getirmeyi hedeflemiştir. Tekstil tasarımında QR kod uygulamasında kullanılan teknikleri ve oluşturacağı koleksiyonda hangi 
tekniği kullanabileceğini araştırmış ve film baskı yapmaya karar vermiştir. Ancak bu baskıların tekstil tasarımı açısından daha fazla estetik bir değer içermesi açısından photoshop programında, QR kod doku efektleri üzerine çalışmış ve dantel etkisi veren bir doku uygulamasına karar vermiştir. Koleksiyonda siyah ve beyaz kontrastlık yaratmak için; geçişli sarı renk ise işitme engellilerle aramızda bir fark olmadığına vurgu yapmak için seçilmiştir.

QR kod'un web adresine gönderme yapabilme ve bir metnin QR kod'a dönüştürülme özelliğinden yararlanarak işitme engellilerin sorunlarını anlatan resim, video, manifesto metni gibi farklı anlatım araçlarına mini koleksiyonuyla yönlendirme yapmıştır.

\section{Tasarımlar}

Üç adet giysiden oluşan mini koleksiyondaki her bir giysi için ayrı ayrı QR kod'lar hazırlanmıştır. Birinci giyside işitme engellilerin sorunlarını anlatan ve öğrenci tarafından hazırlanan bir metin, altı paragrafa bölünerek altı QR kod hazırlanmıştır (Resim 6-11).

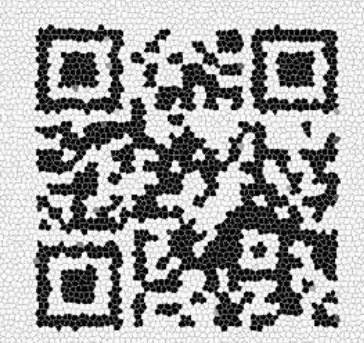

Ben bir işitme engelliyim, bu benim manifestom,sesim!

Yaşadığımız sorunlara sizin de ses vermenizi istiyorum.

Resim 6. 1. paragraf ve QR kod uygulaması

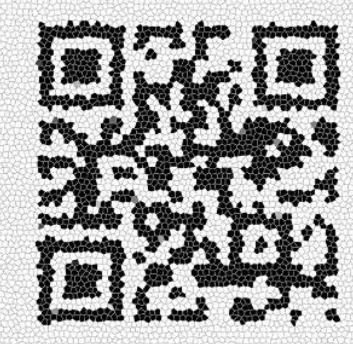

iṣitme engellilerin, her daim avutulmaya, acınmaya, fuzuli yardımlara istiyaçlan yoktur. Biżer sizler gibiyiz,aynlmaz bir bütünùz yaşarken

lẹ sesimizle büyūttüğümüz her şẹi jine sizlere dōndürmek daha çok ulaştırnak

ve bu düşünncelerimizi pine sizlere ulaștırnak istiyoruz!

Resim 7. 2. paragraf ve $Q R$ kod uygulaması

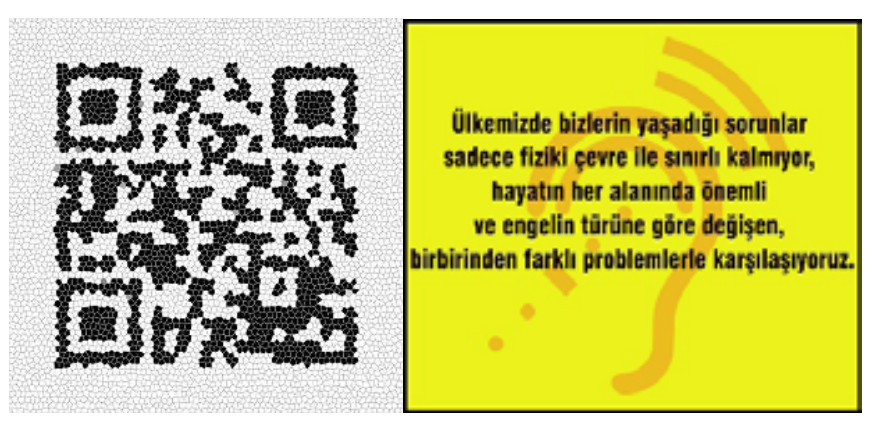

Resim 8. 3.paragraf ve $\mathrm{QR}$ kod uygulaması

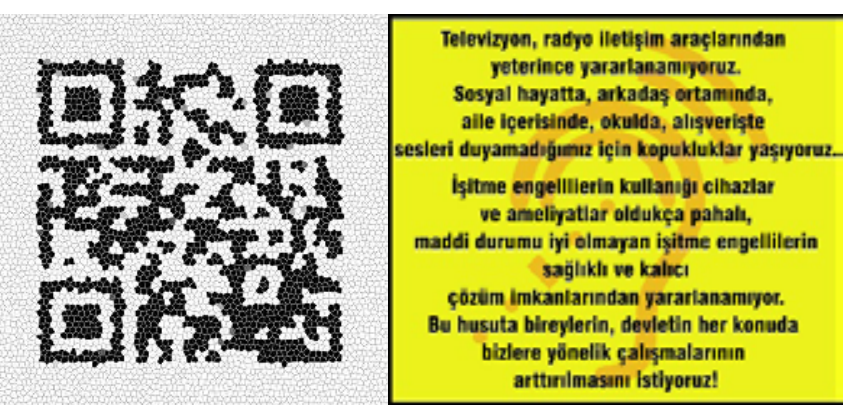

Resim 9. 4.paragraf ve $Q R$ kod uygulaması

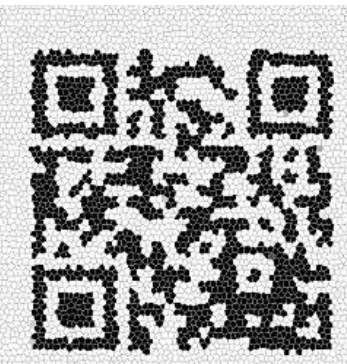

Ailelerin işitme engelli çoçuklan için, erken tanı için bilinçlendirilmesini ve okul ōncesi egitimle bunun gelişimini daha sosyal, kontrollû yapilmasım istiyoruz!

Okullarda herhangi bir aynma gitmeden, ancak bizlere yönelik daha etkin ve entegrasyonu yūksek bir eğitim sisteminin içinde yer almak istiyoruz!

Resim 10. 5. paragraf ve QR kod uygulaması

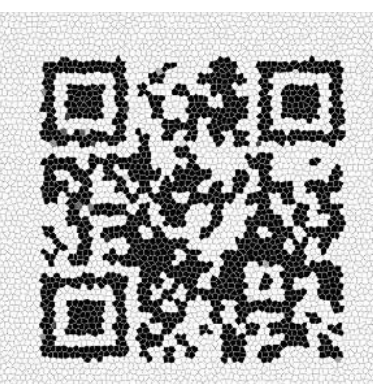
Gelişen teknolojiyle eğitim, sosyal, kültürel iş, aile ve diğer koşullarda bizlere yőnelik yapilan inovasyonun daha çok arttıImasını
ve bireysel olarak sizinle daha iyi bir iletișim ve etkileşim için 'Işaret Dili' öğreniminin yaygınlaştınlmasını istiyoruz! Hey!
Bizlerde buradayn! Bize daha çok ses verin!

Resim 11. 6.paragraf ve QR kod uygulaması 

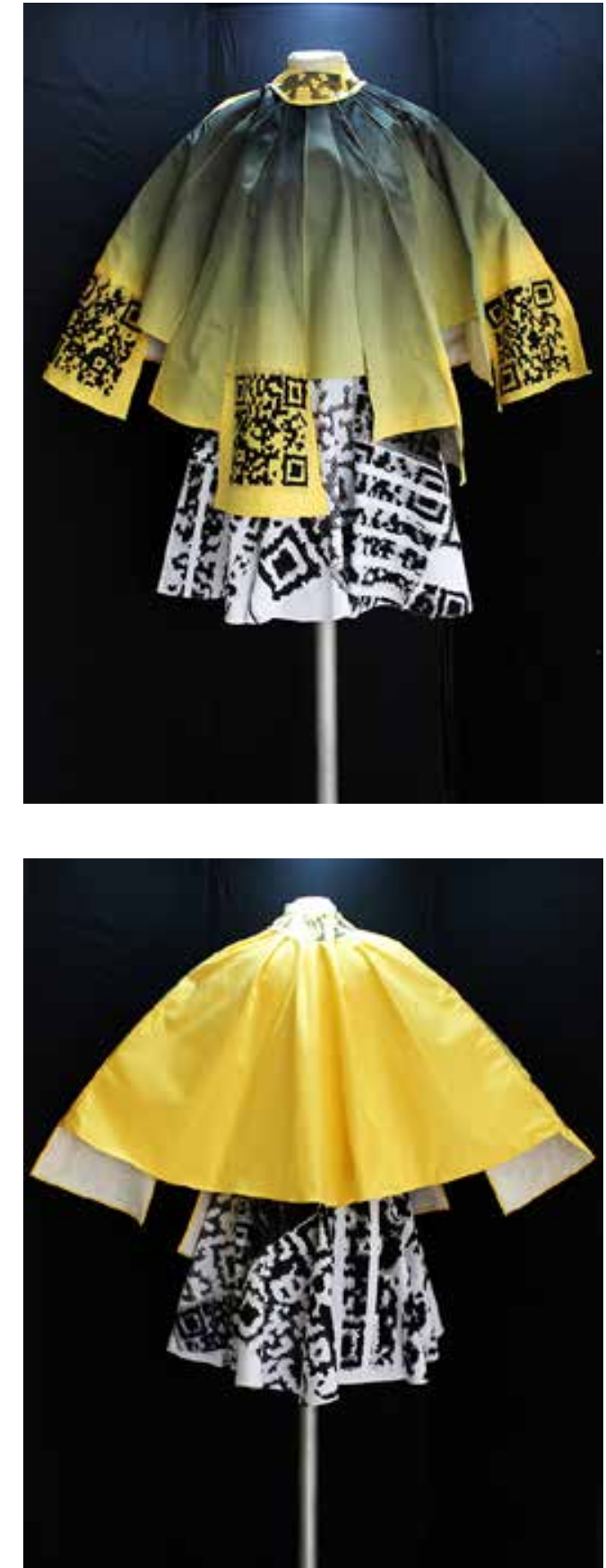

Resim 12. I.Giysi tasarımı, önden ve arkadan görünüş, Ö. Cömertpay, 2015

İkinci giyside işitme engelli bir çocuğun yaptığı resme, işitme engelli iki kişinin yazdığı şiire, sesini alet yardımılla ilk kez duyan işitme engelli bir kadına ve üniversite öğrencileri tarafından işaret diliyle hazırlanmış bir şarkı videolarına yönlendiren QR kod'lar oluşturulmuştur (Re$\operatorname{sim} 13-16)$.
Üçüncü giyside ise işitme engellilerin eğitim haklarını anlatan işaret diliyle hazırlanmış bir videoya, işitme engellilerin acil telefon numaralarını kullanamamalarına dikkat çeken kısa bir filme ve projesinden dolayı işitme engelli arkadaşları tarafından (Derya Dedeoğlu) proje sahibine gönderilmiş bir teşekkür videosu ve projenin son sözünü içeren bir metne yönlendirilme yapılmıştır (Resim 19).

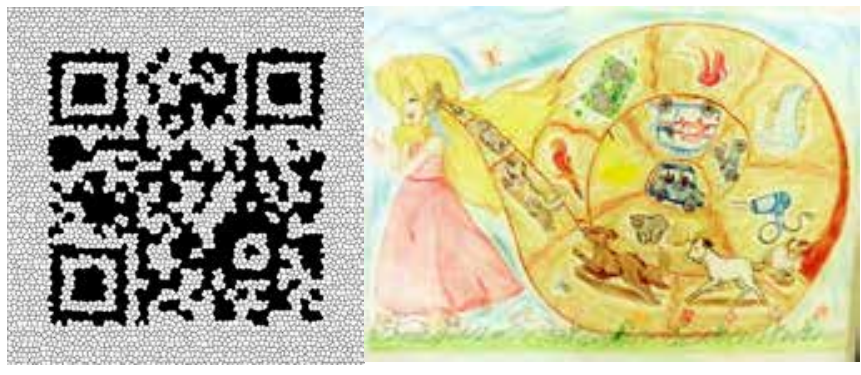

Resim 13. İşitme engelli bir çocuğun yaptığı resim

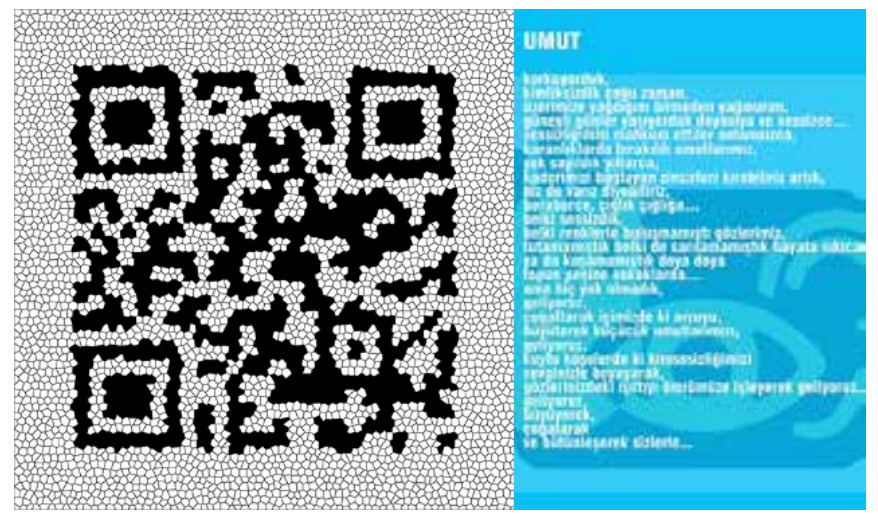

Resim 14. İşitme engelli iki kişinin yazdığı şiir

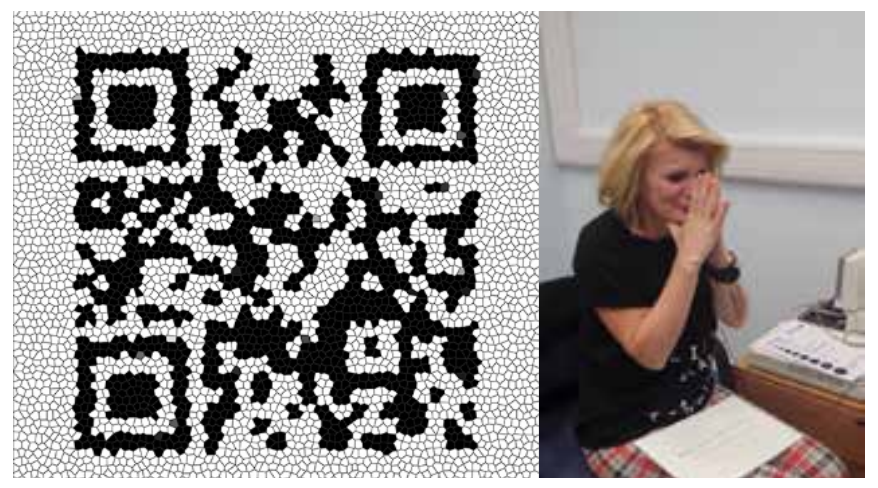

Resim 15. sesini alet yardımıyla ilk kez duyan işitme engelli bir kadının videosu 


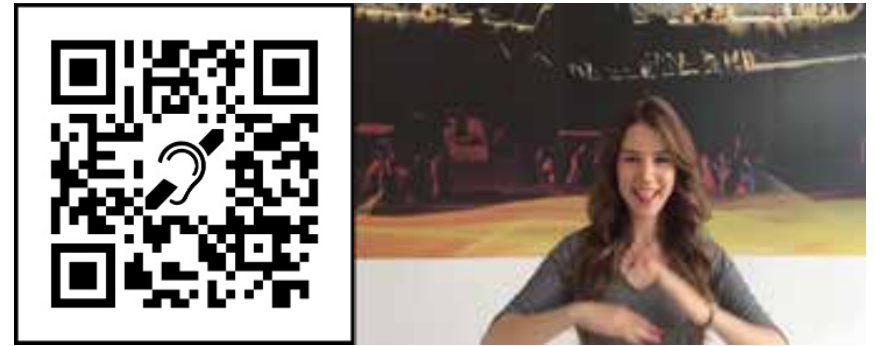

Resim 16. İşitme engelliler için hazırlanmış bir şarkı videosu

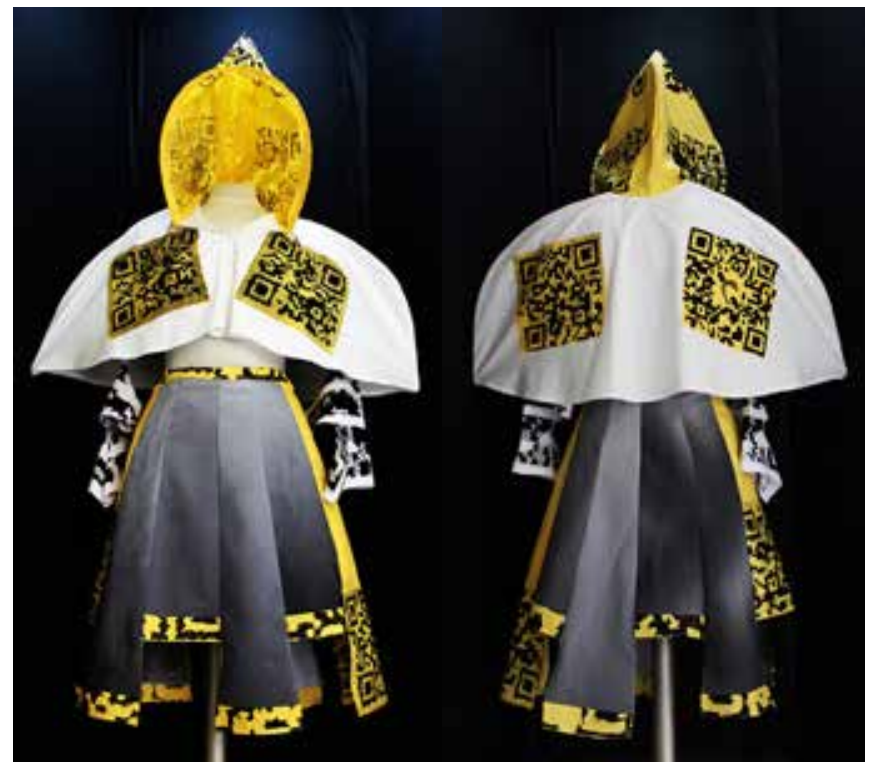

Resim 17. II. Giysi tasarımı, önden ve arkadan görünüş,

Ö. Cömertpay, 2015

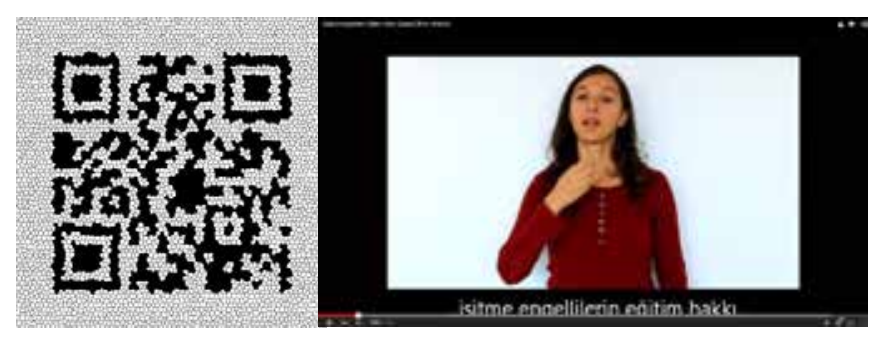

Resim 18. İşitme engellilerin eğitim haklarını anlatan işaret dili ile hazırlanmış video

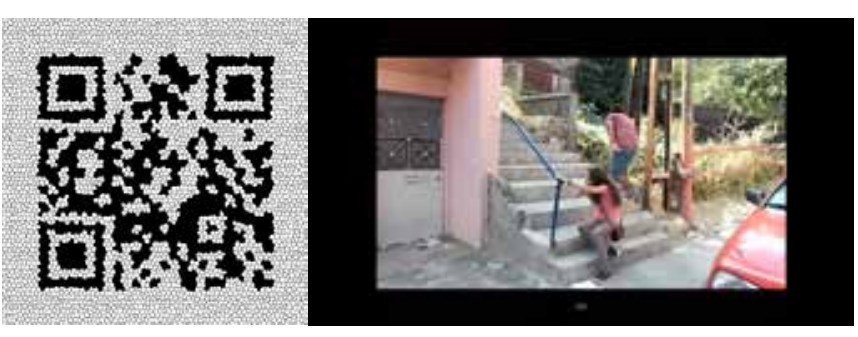

Resim 19. Acil telefonlara ulaşma zorluğunu anlatan film

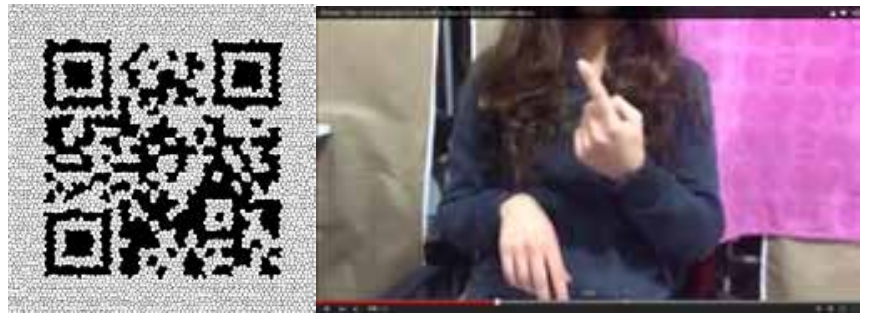

Resim 20. Bir işitme engellinin Ö.Cömertpay’a teşekkürü

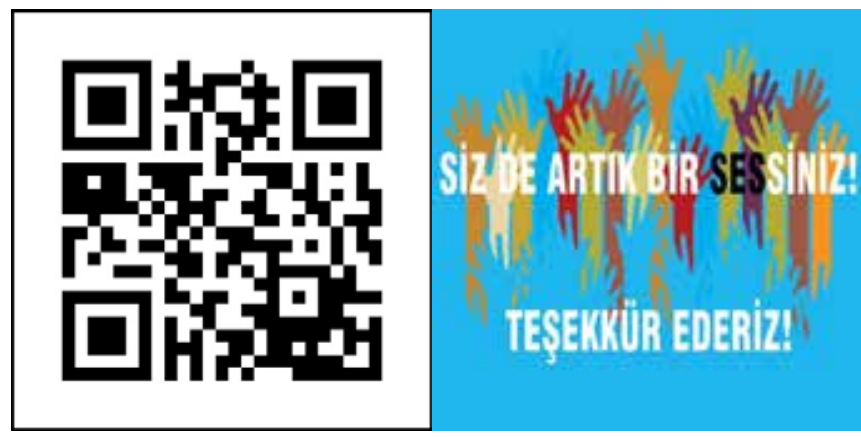

Resim 21. Son söz

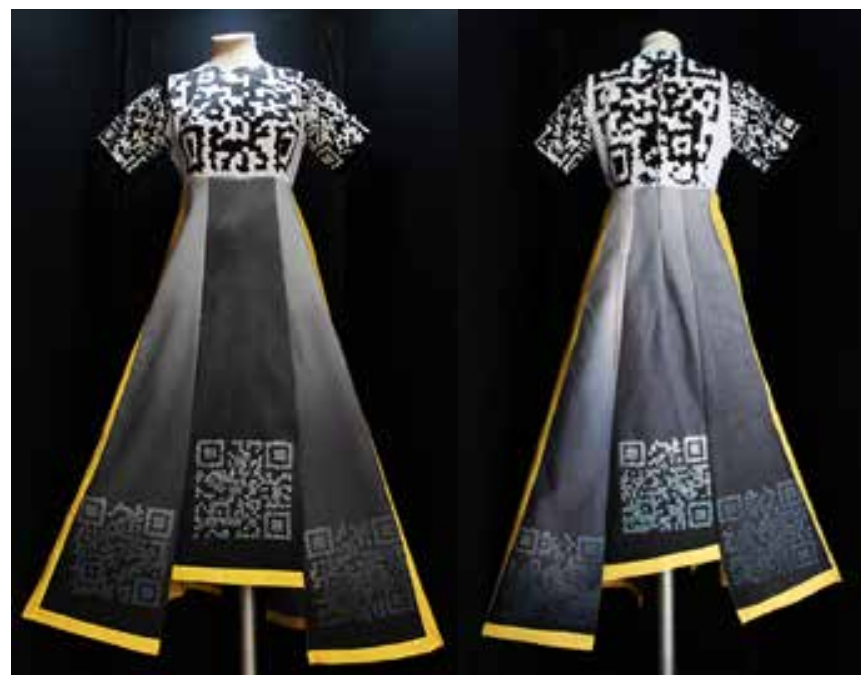

Resim 22. III. Giysi tasarımı, önden ve arkadan görünüş,

Ö. Cömertpay, 2015.

\section{Sonuç}

İnsan yaşam ve konforunu arttırmaya yönelik teknolojik uygulamalar her geçen gün yaygınlaşmaktadır. İletişim teknolojilerinin gelişmesi bilginin kirlenmesine ve hızlı tüketilmesine neden olmaktadır. Bu çağın bir sorunsalı olarak teknolojinin getirdiği hızın içinde kaybolmadan, teknolojinin sağladığı yeni olanakları insanlık adına kullanmak gittikçe önem kazanmaktadır. Tarihten günümüze 
malzeme, desen, renk, doku, model vb. gibi tasarım özellikleriyle sembolik anlamlar taşıyan giysiler, dijital bilgi taşıyan QR kodlarla benzer işlevleri görmüşlerdir. Tekstiller ve $Q R$ kodlarda ortak olan bu mesaj taşıma işlevi, tekstillerde QR kod kullanımıyla daha da zenginleştirilebilme olanağına sahiptir.

Sosyal mesajlar içeren QR kod'ların, çağın teknolojisi ve sanatsal yaklaşımının bir sentezi olarak tekstil tasarımıyla daha estetik olacă̆ı, mesajı daha anlamlı kılacağı ve daha fazla bir farkındalık yaratacağı düşünülmektedir.

\section{Kaynakça}

Hung-Kuo Chu, Chia-Sheng Chang, Ruen-Rone Lee, Niloy J. Mitra, (2013) Halftone QR Codes, ACM Transactions on Graphics, $32,6,217: 1-8$

Lin Yi-Shan, Luo Sheng-Jie, Chen Bing-Yu, (2013), Artistic QR Code Embellishment, Pacific Graphics, 32, 7, 137-146

Manoj S. Rewatkar and Shital A. Raut, (2014) "Survey On Information Sharing Techniques Using QR Barcode", International, Journal on Cryptography and Information Security (IJCIS), 4 (3):13-20.

0'Callaghan Simone, (2009) Art and Mobile Augmentation The Brave New World of Graphical Tagging, 397, 1-6

Roebuck, Kevin (2012), QR code: High-impact Strategies - What You Need to Know: Definitions, Emereo Publishing

Winter Mick,(2011), Scan Me - Everybody's Guide to the Magical World of Qr Codes, Westsong Publishing, USA.

\section{İnternet Kaynakları}

Kuusk Kristi, Wensveen Stephan, Tomico Oscar, (2014) “Crafting Qualities in Designing QR-coded Embroidery and Bedtime Stories" The Art of Research, Helsinki, 1-12, http:// designresearch.aalto.fi/events/aor2014/papers/Kuusk.pdf http://www.academia.edu/8284908/Art_and_Mobile_ Augmentation_The_Brave_New_World_of_Graphical_ Tagging, Conference Paper, Abertay University. School of Arts Media \& Computer Games

Rubi McGrory, http://www.qrdresscode.com/article-qr-codeplaid-49994651.html, Erişim tarihi: 30.03.2015

\section{Görsel Kaynaklar}

Resim 1: Lukutuwe (Fertility), Guillermo Bert 2012; Wool, encoded with Aztec bar code and eight minute documentary video; 90 " $x$ 60" Collection of the artist, Kaynak: Textile Society of America, Exhibition Brochure, 2015 p.4) http:// textilesocietyofamerica.org/wp-content/uploads/2013/12/ Juried-Show-Booklet-FINAL.pdf, Erişim: 12.05.2015
Resim 2: Boncuk işlemeli barkod, Thorunn Arnadottir, 2011, http://fashioningtech.com/profiles/blogs/beaded-qr-codegarment, Erişim:30.03.2015

Resim 3: Baskı tekniği ile QR kod uygulaması, Vincent Simoncelli, 2011, http://www.coroflot.com/3dgrafx/kufik-calligraphyand-qr-code-stamps, Erişim: 30.03.2015

Resim 4: QR desenli eldiven, Donna Druchunas, 2015, http:// webrazzi.com/2012/01/31/10-yaratici-qr-kod/, Erişim: 30.03.2015

Resim 5: Rubi McGrory, Patchwork, 2010http://www.qrdresscode. com/article-qr-code-plaid-49994651.html, Erişim: 30.03.2015

Resim 6: 1. paragraf ve QR kod uygulaması, Ö. Cömertpay, 2015

Resim 7: 2. paragraf ve QR kod uygulaması, Ö. Cömertpay, 2015

Resim 8: 3.paragraf ve QR kod uygulaması, Ö. Cömertpay, 2015

Resim 9: 4.paragraf ve QR kod uygulaması, Ö. Cömertpay, 2015

Resim 10: 5. paragraf ve QR kod uygulaması, Ö. Cömertpay, 2015

Resim 11: 6.paragraf ve QR kod uygulaması, Ö. Cömertpay, 2015

Resim 12: 1.Giysi tasarımı, önden ve arkadan görünüş, Ö. Cömertpay, 2015

Resim 13: İşitme engelli bir çocuğun yaptığı resim, http://twicsy. com/i/Ji8uEe, Erişim: 05.05.2015

Resim 14: İşitme engelli iki kişinin yazdığı şiir, (Nurdoğan DurakEzgi Koyuncu,

http://www.dersimiz.com/siir-5277-Umut.html\#. VV3Q5fntmko, Erişim: 19.05.2015

Resim 15: sesini alet yardımıyla ilk kez duyan işitme engelli bir kadının videosu,

http://www.dailymotion.com/video/x1kjo3c_40-yasindailk-kez-duyan-kadin_news, Erişim:30.03.2015

Resim 16:İşitme engelliler için hazırlanmış bir şarkı videosu, “Keyfi Yolunda, Aşkı Sonunda”, https://www.youtube.com/ watch?v=FXIJiP1e-y4, Erişim 12.05.2015

Resim 17: 2. Giysi tasarımı, önden ve arkadan görünüş, Ö. Cömertpay, 2015

Resim 18: İşitme engellilerin eğitim haklarını anlatan işaret dili ile hazırlanmış video, https://www.youtube.com/ watch?v=DrKZF4bIn2g, Erişim: 03.2015

Resim 19: Acil telefonlara ulaşma zorluğunu anlatan film, https:// www.youtube.com/watch?v=K9IWizrb81A, 19.05.2015

Resim 20: Bir işitme engellinin Ö.Cömertpay’a teşekkürü, https:// www.youtube.com/watch?v=0sxS95qhGCA, Erişim: 09.05.2015 
Resim 21:Son söz, Ö. Cömertpay, 2015

Resim 22: 3. Giysi tasarımı, önden ve arkadan görünüş,

Ö. Cömertpay, 2015

\section{Kaynak Kişiler}

Derya Dedeoğlu, İstanbul

Yasemin Dönmez, Kütahya

Naime Dönmez, Kütahya 